Review

\title{
On Concept of Hybrid in Colloid Sciences
}

\author{
Camillo La Mesa ${ }^{1, *}$ and Gianfranco Risuleo ${ }^{2,+}$ \\ 1 Department of Chemistry, La Sapienza University of Rome, Piazzale Aldo Moro, 5, 00185 Roma, Italy \\ 2 Department of Biology and Biotechnologies "Charles Darwin", La Sapienza University of Rome, \\ Piazzale Aldo Moro, 5, 00185 Roma, Italy; gianfranco.risuleo@uniroma1.it \\ * Correspondence: camillo.lamesa@uniroma1.it \\ + Retired.
}

check for updates

Citation: La Mesa, C.; Risuleo, G. On Concept of Hybrid in Colloid Sciences. Colloids Interfaces 2021, 5, 33. https:// doi.org/10.3390/colloids5020033

Academic Editor: Reinhard Miller

Received: 31 March 2021

Accepted: 8 May 2021

Published: 9 June 2021

Publisher's Note: MDPI stays neutral with regard to jurisdictional claims in published maps and institutional affiliations.

Copyright: (C) 2021 by the authors. Licensee MDPI, Basel, Switzerland. This article is an open access article distributed under the terms and conditions of the Creative Commons Attribution (CC BY) license (https:/ / creativecommons.org/licenses/by/ $4.0 /)$.

\begin{abstract}
The concepts hybrid and hybridization are common in many scientific fields, as in the taxonomic parts of botany and zoology, in modern genetic, and in the quantum-mechanical theory of atomic-molecular orbitals, which are of foremost relevance in most aspects of modern chemistry. Years later, scientists applied the concept hybrid to colloids, if the particles' domains are endowed with functionalities differing each from the other in nature and/or composition. For such denomination to be fully valid, the domains belonging to a given hybrid must be recognizable each from another in terms of some intrinsic features. Thus, the concept applies to particles where a given domain has its own physical state, functionality, or composition. Literature examples in this regard are many. Different domains that are present in hybrid colloids self-organize, self-sustain, and self-help, according to the constraints dictated by kinetic and/or thermodynamic stability rules. Covalent, or non-covalent, bonds ensure the formation of such entities, retaining the properties of a given family, in addition to those of the other, and, sometimes, new ones. The real meaning of this behavior is the same as in zoology; mules are pertinent examples, since they retain some features of their own parents (i.e., horses and donkeys) but also exhibit completely new ones, such as the loss of fertility. In colloid sciences, the concept hybrid refers to composites with cores of a given chemical type and surfaces covered by moieties differing in nature, or physical state. This is the result of a mimicry resembling the ones met in a lot of biological systems and foods, too. Many combinations may occur. Silica nanoparticles on which polymers/biopolymers are surface-bound (irrespective of whether binding is covalent or not) are pertinent examples. Here, efforts are made to render clear the concept, which is at the basis of many applications in the biomedical field, and not only. After a historical background and on some features of the species taking part to the formation of hybrids, we report on selected cases met in modern formulations of mixed, and sometimes multifunctional, colloid entities.
\end{abstract}

Keywords: hybrids; organic moieties; inorganic domains; cores vs. surfaces; biological functionality; thermodynamic/kinetic stability; technological applications; bio-medicine

\section{Introduction: Hybrids, Freaks and Visions}

The concept of hybrid takes its origin from both the classical literature and mythology, where sphinxes, hermaphrodytes, medusae, chimerae, centaurs, and similar entities were considered real [1]. The underlying reason finds origin in the fact that humans imagined (and somehow still do) that entities joining the properties of diverse animal types in a new one, whatever imaginary it could be, ensured to the resulting hybrid peculiar properties such as bisexuality, the contemporary attitude to walk, swim, and fly, and a wide number of funny, sometimes horrible, combinations of characters, as shown in Figure 1.

In the bestiaries of the middle ages, and later, many examples of that sort were considered and beautifully drawn by monks (who were outstanding miniaturists) and artists [2]. Consider, for instance, the superb, disquieting, pictures by the Dutch painter Hieronymus Bosch, or the fruit/human portraits by Arcimboldo. Grotesque and gruesome creations are not alien to the imagination of J. Boss-chart, a Dutch artist of our times. Also 
René Magritte created surrealistic "hybrid figures"; see Figure 2. We do not forget, anyhow, Pablo Picasso, Salvador Dali, and other surrealist painters!

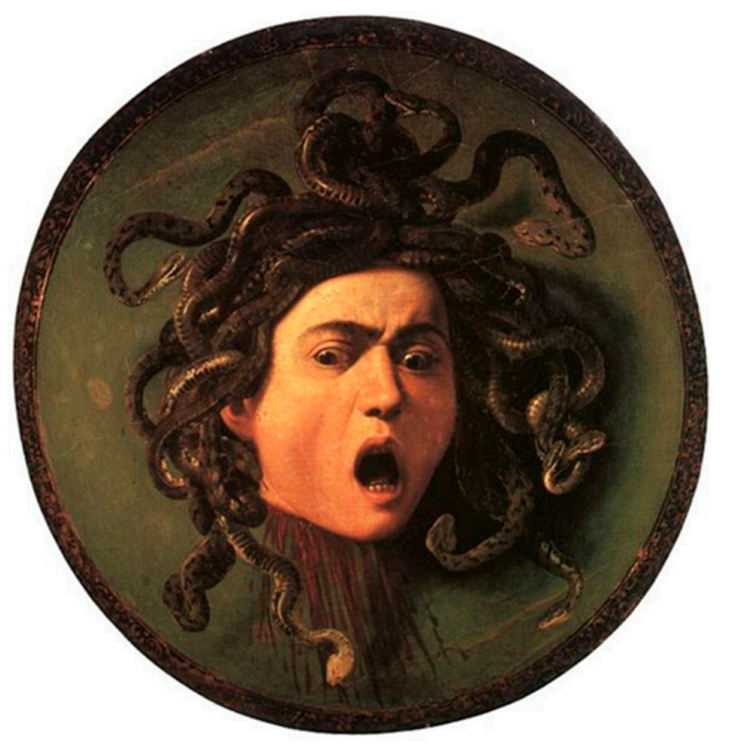

Figure 1. Mythological hybrid, wonderfully painted by Caravaggio in the Shield with Medusa head, oil on canvas, dating 1595-1598, Museo degli Uffizi in Florence, Italy. It takes inspiration from classical literature. Blood is flowing from the neck and eyes are horrified by Medusa's self-viewing on Perseus' bronze shield before being beheaded by her opponent. Not all artists of the past were as brutally frank as Caravaggio. In his Metamorphoses, Ovidius claims that Perseus is taken from pity toward his victim and puts Medusa's head on a bed of algae, so that "anguiferumque caput dura ne laedat harena" (i.e., "so that the hard sand will not injury the eel-covered head").

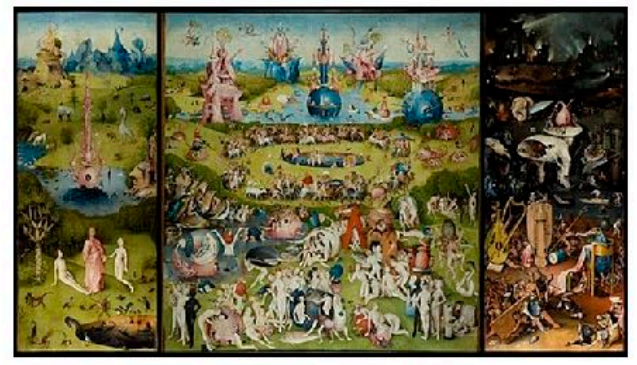

$\Lambda$
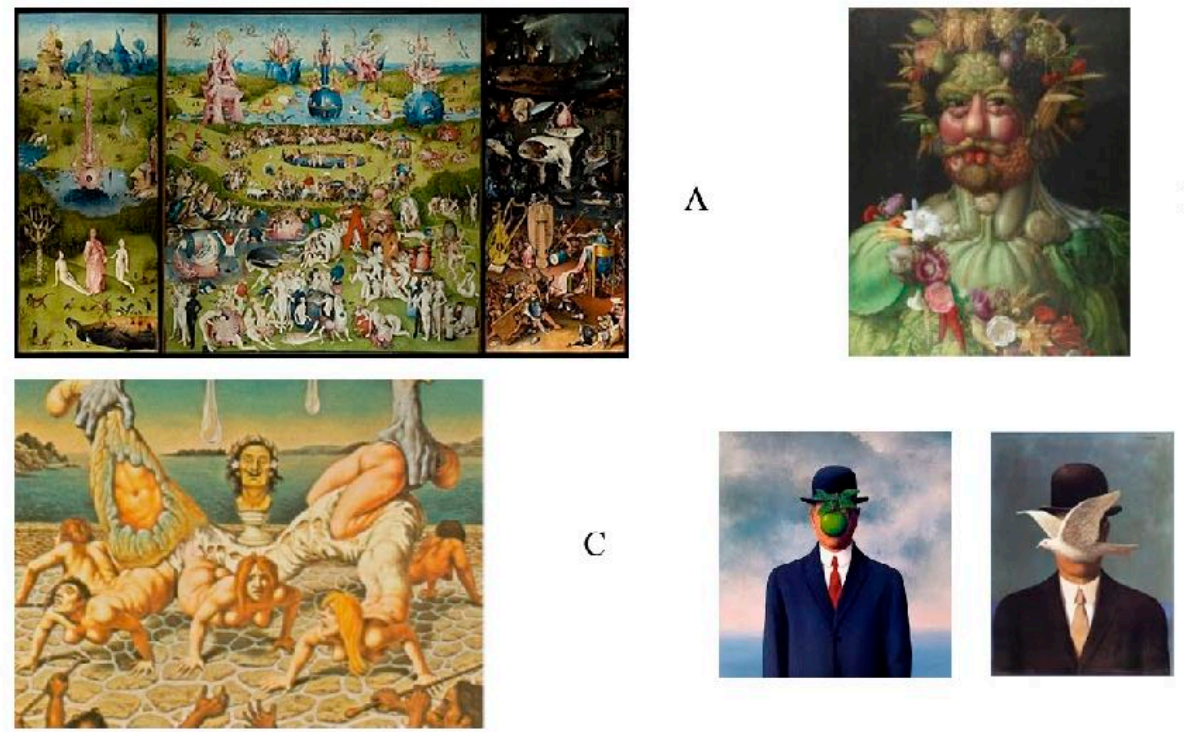

D

Figure 2. (A): The famous tryptich "The Garden of Earthly Delights" (oil on oak panel) by Hyeronimus Bosch. It is exposed at the Museo del Prado in Madrid. (B): Painting (oil on wood) of the Roman God of the seasons, Vertumnus, by Biagio Arcimboldo (also spelled Arcimboldi), today kept at Gripsholm Castle by the Malarian lake, Sweden. (C): "The Apotheosis of Dalí ", by Johfra Bosschart, 1971, appearing on a book by he himself "Highest Lights and Deepest Shadows". Information about him is not abundant. He is known as an eccentric and extravagant, but fascinating, artist whose work offers a very hard perusal. (D): The visionary art of Renè Magritte is evident in two paintings, named, respectively, "Men's son", left, and "Man with bowler hat", 1964, actually kept in private collections. 
Strictly speaking, angels and devils too belong to the category of hybrids. From that fact comes out a general consideration, stating that humans always dreamed about the possibility that attitudes peculiar to a given category could fruitfully mix with those pertinent to a second one.

Concerning "natural" plant and animal hybrids and selections, let us mention that the end of the hunters-gatherers era grossly coincides with the beginning of routinely agricultural practices and animal husbandry [3]. As a consequence, humans became bound to a stable site and sedentary. This avoided them the continuous and uncertain labor of hunting and collecting fruits or roots. Breeding started with the sedentary lifestyle and domestication of the first agricultural plants, estimated to date back 9000 to 11000 years ago [4]. Grafting methods were common in China before 2000 BCE [5]. Early farmers selected edible plants having particular features and employed these as progenitors for subsequent generations, with the accumulation of valuable traits over time. Husbandry generated animal hybrids: for instance, in ancient Egypt, cattle were very important livestock, and sheep, goats, and pigs were also kept. Poultry included ducks and geese; pigeons were captured in nets and bred on farms, where they were force-fed with dough to fatten them. Honeybees were domesticated from at least the Old Kingdom age, providing both honey and wax [6,7]. In ancient Rome, rabbits were domesticated for food before the first century BC. To help flush them out from their burrows, polecats (Mustela putorius) and ferrets (Mustela putorius furo) were domesticated, as documented by Pliny the Elder (AD 23/24-79 of our era) [8-10]. This Roman historical naturalist and philosopher documented the domestication and usage of ferrets (that he named meles) in Roman provinces, as the Balearic Islands. Polecat-ferret is a hybrid by a wild European polecat and a domesticated ferret. It is not easy to distinguish polecats from their hybrids through DNA analysis, due to extensive gene inter-mingling. Supposedly, the escape of domesticated ferrets has led to the hybridization of ferrets and polecats in the wild.

In modern bio-sciences, the concept of hybrid is not restricted to organisms resulting from in vivo or in vitro genetic mixing. In fact, the word chimerism indicates organisms composed of cells having more than one genotype. At a cellular level, all living beings, be they animals or plants, are chimeras. Animal cells contain mitochondria, playing a key role in respiration, whenever plants contain chloroplasts, which are active in photosynthesis. Both kinds of organelles are ancestral symbionts of the respective cells and are endowed of their own genotype (DNA). This makes, by definition, all cells as functional chimeras. At the molecular level, the formation of hybrid molecules occurs during DNA replication and transcription into RNA chains. Any animal type has his or her own appearance (the phenotype) directly determined by its DNA genetic patrimony. Despite that, female and male sex organs may coexist in the same individual, no matter whether is its gender: it is the regulation of different genes that triggers the prevalence of one phenotype [11]. Even transitions from an animal type to another, such as whales and hippos, are explained on the same grounds [12].

Gene dis-regulation may give rise to hermaphrodites, although these are quite rare in nature. Organ transplant technologies made chimeras a surgical phenomenon: it is not possible to define in other ways the recipient of a transplanted heart or liver from a deceased donor. In addition, bone marrow transplantation may determine the recipient's ensuing blood type [13]. Myeloma repair in modern medicine takes origin exactly from the same approach [14]. This concept is synthesized in the famous Latin allocution by Gottfried W. Leibniz "Natura non fecit saltus" (Nature never makes leaps) to indicate the evolutionary continuity, when expressed in terms of mathematical functions [15]. The same concept was later adopted by Carl von Linné (Carolus Linnaeus) in his "Systema naturae", where he established that biological species form a continuum of variations, generating over time many different plants and animals [16]. 


\section{A Brief Historical Background on the Concept of Hybrid in Chemistry}

In chemical investigations dating to the 19th and 20th centuries, the concept of hybridization was widely used to define the chemical structure of benzene [17], and later, the theory of atomic/molecular hybrid orbitals leading to the concept of LCAO (Linear Combination of Atomic Orbitals) [18-22]. The underlying theory is firmly based on quantum-mechanical approaches.

As to the concept of hybrid in Colloid Sciences, a lot more can be said. Originally, the word Colloid took its definition in a "negative" sense, due to the difficulty to crystallize these materials with respect to Crystalloids. Substantial investigations from Ostwald, founder of the first journal on colloids [23,24], and others took place. Ostwald himself had at his disposal the possibility to see real examples of association colloids, thanks to the suggestions of McBain [25], but he rejected such possibility with disdain [26]. The concept of association colloids, the first to be discovered as a class, was described by McBain. "Colloidal electrolytes are salts in which an ion has been replaced by a heavily hydrated polyvalent micelle that carries an equivalent sum-total of electrical charges and conducts electricity just as well or even better than the simple ion it replaces" [27]. Perhaps, the concept of association colloids was fully accepted only in the 1930s [28].

A few years later, polymer chemistry started being considered a field of research autonomous and independent from the consolidated colloid chemistry. This is due to the pioneering contribution of E. Staudinger, the first polymer chemist awarded with a Nobel Prize in 1953 (despite his landmark papers date back to the 1920s) [29-31]. Nobody at that time thought of the possibility to join the two categories in a single one, since scientists were trying to do the reverse in such a way to distinguish them. Imagine how risky it could have been in those years introducing the term "hybrid colloid"!

The modern concept of hybrid colloids took place only recently, despite sparse excellent contributions in the field. The first approach along this line is surely due to Feynman in the seminal article "There's plenty of room at the bottom" [32], although the term "hybrid" does not explicitly appear therein. Anyhow, the inclination toward the concepts of nanotechnologies, including hybrids, surely originated from Feynman's contribution.

Effective attempts to proceed on their preparation and characterization took place since the 1950s, when bodies based on polymers, slurries, nanoparticles, or fine powders were covered with species adsorbing thereon and ensuring them with a substantial kinetic stability. The increase in the number of functionalities and in the preparation pathways was very fast until the ubiquitous use nowadays. The category can be extended to covered surfaces [33], fibers [34], and so forth. For brevity, we do not mention here emulsion droplets. This would lead us to talk about a much wider field of applications.

Combining the features of intrinsic (that we actually term solid, semi-solid, nanoparticles) and association colloids gives the opportunity to obtain hybrid entities. It is worth noting that the concept of hybridization originally came from the necessity to avoid undesired clustering of silver nanoparticles (the first to be synthesized and extensively used for biomedical purposes); see in Figure 3.

These entities, which may preferentially assume the form of platelets in the given working conditions, spontaneously collapse if not properly surface-covered [35]. Another important point to mention is that coverage by a given species may prevent the undesired adsorption of unwanted ones. A relevant example deals with use of $P E O$ (i.e., polyethylene oxide), avoiding adsorption of proteins on $\mathrm{SiO}_{2}$ colloid particles intended for in vivo administration [36]. This is the main reason why biomedical competences are needed to implement the behavior of systems like such. 


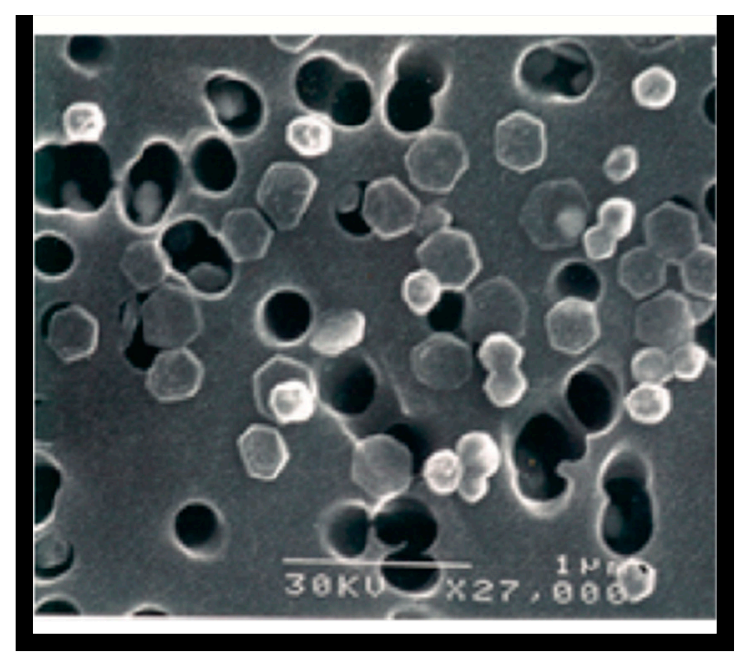

Figure 3. Hexagonal in shape silver platelets deposited on a polycarbonate membrane. They were obtained by reduction in the presence of an adsorbent. The bar size is $1.2 \mu \mathrm{m}$ long. Partly redrawn from Ref. [32].

\section{More Remarks}

\subsection{Generals}

Let us consider finely dispersed bodies, which spontaneously tend to collapse. The physical state of such bodies is immaterial. Adsorbate and adsorbent, the categories on which we focus, interact thanks to the formation of covalent bonds or non-specific chemical linkage. In both cases, the final product is stable and moves in the solvent as a whole kinetic entity (N.B. An example can be the covalent binding of $\mathrm{C}_{18} \mathrm{OH}$ onto silica). It is immaterial if such "stability" is thermodynamic, or kinetic, in nature. Energy barriers controlling the stability of all hybrids can be many $\mathrm{k}_{\mathrm{B}} \mathrm{T}$ units high. It is not surprising that although the energy pertinent to the non-specific binding on a single locus, as an hydrophobic surface, is relatively low (about $2.5 \mathrm{~kJ} \mathrm{~mol}^{-1}$ per $\mathrm{CH}_{2}$ units [37]), the system as a whole is substantially stable, since the number of "weak" (of van den Waals, vdW, nature) surface bonds that are formed is extremely high. The effect is cooperative but partly counteracted by steric effects, and this ensures that although coverage effectively takes place, surface crowding is almost never attained.

Surface functionality (termed wrapping) is described in the following. Imagine having a dispersion of spherical particles having the same radius, embedded in a medium containing size-mono-dispersed polymers. Whatever their nature, polymers wrap onto nanoparticles and impart them substantial stability, avoiding coagulation and undesired phase separation. The above effects are controlled by the overlapping of different energy contributions. In the case of covalent interactions, bonds are formed by chemical reaction; the final products are stable for indefinite long times. In the non-covalent mode, polymer portions adsorb on the nanoparticles' surface (hereafter indicated as NPs), other parts face outside; the non-interacting parts are randomly dispersed in the bulk. The forces responsible for wrapping can be extremely diverse in their nature and span from pure $\mathrm{vdW}$ [38] to purely electrostatic [39].

Some relations for the (wrapping/protruding) ratio are known, and energy contributions to wrapping have been quantified. Changes in the conformational degrees of freedom for surface-bound polymers are relevant in the stability of aggregates they form with NPs. Wrapping is controlled by many energy terms, jointly contributing to stabilization. They include both surface-polymer and polymer-polymer interactions, and interactions with the solvent (mostly for polymer chains), as well. Similar considerations apply to particle-protein systems and particle-surfactant hybrids. The latter case is similar to that of polymer adsorption [40], with significant differences [41]. Surfactants adsorb on non-polar surfaces by hydrophobic interactions. Cases are known where their ionic groups anchor by 
electrostatic forces on the particles and neutralize them. Later, a second adsorption stage takes place [42]; in words, vesicle bilayers confine NPs.

The generalities of adsorption are described in the following paragraph. Below, we would stress on the concept, stating that hybrids in colloid science imply many significant variations with respect to the parent entities, generating different organization modes and functionalities. The above concept has real pertinence with what is formerly described in the behavior inherent to cells and tissues. We introduce below a simple approach to the formation of polymer/nanoparticle hybrids. The underlying theory has been simplified, without loss in generality.

\subsection{Polymer-Coated Hybrid Formation: Some Thermodynamic Remarks}

Efforts started in the 1950s, when many authors developed statistical thermodynamics methods, introduced by Flory [43,44], extended to wrapping refined theories, or draw innovative experimental approaches [45-51]. Although many years have passed from Flory, there are still some obscure points in such developments [52,53].

We introduce here a model based on the more currently accepted developments in the field. It applies to "hard" particles such as $\mathrm{SiO}_{2}, \mathrm{TiO}_{2}$, or carbon nanotubes (CNTs), but it can be extended to different entities, be they rigid, soft, or semi-soft. NPs are supposedly uniform in size; the same can be said for polymer chains, which presumably have a mean full length. Whatever such length is, the end-to-end distance for polymers is lower than the NPs diameter, and the length of wrapping units is lower than the fully extended polymer one. Supposedly, polymers and NPs are mono-dispersed in size. This is not a strict requirement and can be overcome using a statistical distribution of particles or polymer sizes. Only part of a polymer chain effectively wraps. These effects are accounted for by defining $\alpha$ as the number of wrapping units per chain. The partitioning of units between the bulk and bound states occurs. We define $X_{f}$ as the mole fraction of free polymers $\left(<X_{t o t}\right)$; the latter is the sum of wrapped and free states. Completely free polymers may exist as well.

Adsorption occurs in the same way as onion leaves progressively grow layer by layer. In case of multi-layer adsorption holds, the amount of interacting polymer is obtained by summing over all possible $M_{i}$ values the number of adsorbed layers. The $M_{1}$ one is in contact with NPs, whereas $M_{m}$ faces toward the solvent. $N^{\circ}\left(=X_{t o t}\right)$ is the concentration of polymer, and $T$ the number of segments in the main chain. The adhesion probability is expressed by a $P$ term, which is related to $\alpha$. Complementary to $\alpha$ is an $\varepsilon$ term that indicates the fraction of polymer not directly involved in wrapping. $\alpha$ and $\varepsilon$ refer to the whole number of bound/free, states, irrespectively of whether physical continuity in bound sub-domains occurs. The weight of wrapping and protruding parts is expressed as

$$
\begin{gathered}
M \alpha T=\left(1-X_{f}\right) N^{\circ} P^{\alpha}(1-P)^{2} \\
M \varepsilon T=M(1-\alpha) T=\left(1-X_{f}\right) N^{\circ} P^{2}(1-P)^{\varepsilon}
\end{gathered}
$$

where $1 \leq M \leq \mathrm{m}$.

In the onion-like approximation, the equilibrium between $\alpha$ and $\varepsilon$ states in each layer, $K_{\alpha, \varepsilon}$, is expressed as

$$
K_{\alpha, \varepsilon}=\left[\frac{\alpha}{\varepsilon}\right]=\left[\frac{\alpha}{1-\alpha}\right]=\left[\frac{P^{\alpha}(1-P)^{2}}{P^{2}(1-P)^{(1-\alpha)}}\right]
$$

$\alpha T$ and $(1-\alpha) T$ indicate the number of wrapped and protruding units, respectively. Their ratio is controlled by the polymer affinity toward the surfaces, or successive layers, and it is counteracted by the repulsive forces they exert on each other. Since $\alpha$ is directly proportional to wrapping, its value can be calculated by summing Equation (3) over all possible $M_{i}$ values. 
Explicit relations between $\alpha$ and $P$ are obtained assuming that $(1-\alpha)=(1-P) / P[50]$. Thus,

$$
\frac{\alpha P}{1-P}=\left[\frac{P^{\alpha}(1-P)^{2}}{P^{2}(1-P)^{(1-P) / P}}\right]
$$

After partial separation of variables and subsequent re-arrangement of Equation (4), we get

$$
\frac{P^{\alpha}}{\alpha}=\left\{\frac{P^{3}(1-P)^{\frac{1-P}{P}}}{(1-P)^{3}}\right\}
$$

which can be easily transformed in a distribution function.

For homo-polymers, wrapping is controlled by the main chain length, unless the protruding parts contain groups directly involved in binding. We assume the polymers to have uniform cross-section, which is indicated as $a$. Adhesion implies the wrapping of $a$-wide ribbons; obviously, $a$ is an average value.

We introduce an adhesion term, $w$, of dimensions energy per unit area, and $\pi$, an osmotic pressure contribution. The first indicates the transfer energy from the bulk to the NP surface, when $\pi$ is the two-dimensional analogue of an osmotic pressure. The adsorption energy, $E_{a d}$, is related to the wrapping length and is proportional to

$$
E_{a d}=(w+\pi) a l_{i} f_{i}+\eta
$$

Subscripts $i$ in Equation (6) indicate the number of binding entities, $l_{i}$ indicates the extended segment length, and $f_{i}<1$, is a shrinking parameter, which depends on the structure and conformation of segments. $f_{i}$ terms are justified by a possible segment shrinking [54]. The surface coverage reaches a maximum in case of fully extended length, when $f_{i}$ values approach unity. $\eta$, a shrinking energy term, depends on polymer conformation. Its value is not known a priori and is determined by spectroscopic methods [55]. The meaning of $\pi$ and $w$ terms was given above.

The Boltzmann probability for the weight of an $i$ state, $P(\Omega)_{i}$, is related to $E_{a d}$, and is defined as

$$
\mathrm{P}(\mathrm{W}) \mathbf{i}=k_{i} \exp ^{-[(\pi+w) \text { afili/KBT] }} \exp ^{-[\eta / \mathrm{KBT}]}
$$

The term $(\Omega)$ refers to a statistical distribution. $k_{i}$ constants are peculiar to each binding state and are related to the chain stiffness. $k_{i}$ 's and $f_{i}$ 's are interrelated; the stiffer the polymer, the higher is $k_{i}$ and the closer to unity is $f_{i}$. Thus, $P(\Omega)_{i}$ terms are controlled by $k_{i}$. Summing over all possible $i$ states gives

$$
P_{\alpha}=P_{t o t}=\Sigma_{\mathrm{i}=1} P(\Omega)_{i}=\Sigma_{\mathrm{i}=1} k_{i} \exp ^{-[(\pi+\mathrm{w}) \text { afili } / \mathrm{KBT}]} \exp ^{-[\eta / \mathrm{KBT}]}
$$

The above equation relates the wrapping energy to the weight of each possible state. $P(\Omega)_{i}$ terms may differ in $E_{\text {ad }}$ values each from another.

Wrapping effectively occurs if $l_{i} \mathrm{~s}$ in Equation (8) have a non-negligible statistical weight. As a consequence, a maximum in the plot of $P(\Omega)_{i}$ versus $l_{i}$ occurs; its position depends on the segment(s) length. $w$ terms must be significant for the process to be effective.

In calculating the binding of $\mathrm{PEO}$ units onto $\mathrm{SiO}_{2}$, we supposed that its value is twice that for the transfer of a $\mathrm{CH}_{2}$ unit into a micelle interior $\left(600 \mathrm{cal} \mathrm{mol}^{-1}\right)$ [37]. $P(\Omega)_{i}$ is maximum in a narrow $l_{i}$ range and that its position depends on $f_{i}$. The shape of $P(\Omega)_{i}$ curves is not symmetrical with respect to $l_{i}$. The mid-height amplitude of $P(\Omega)_{i}$, its location and maximum, $P(\Omega)_{i, m a x}$, are related to the number of segments. The probability of a given state depends on $a, l_{i}$, and $f_{i}$. Thus, we may write $P(\Omega)_{i}=\mathrm{f}\left(a, l_{i}, f_{i}\right)$. Derivation with respect to control variables gives information on the system stability. Rewriting Equation (10) for each $i$ state leads to

$$
\ln \left(P(\Omega)_{i} / k_{i}\right)=-\left[1 /\left(\mathrm{K}_{\mathrm{B}} \mathrm{T}\right)\right]\left[(\pi+\mathrm{w}) a f_{i} l_{i}-\eta\right]
$$


$\eta$, the planar component of rotational energy for wrapping segments, is an implicit form of $f_{i} l_{i}$. There is only one point in the configurational space defined by $f_{i}$ and $l_{i}$ coordinates at which

$$
\begin{aligned}
& \left(\mathrm{d} \ln \left[P(\Omega)_{i} / k_{i}\right] / \mathrm{d} f_{i}\right)_{l i}=-\left[(\pi+w) a l_{i}-\left(\mathrm{d} \eta / d f_{i}\right)_{l i}\right]=0 \\
& \left(\mathrm{~d} \ln \left[P(\Omega)_{i} / k_{i}\right] / \mathrm{d} l_{i}\right)_{f i}=-\left[(\pi+w) a f_{i}-\left(\mathrm{d} \eta / d l_{i}\right)_{f i}\right]=0
\end{aligned}
$$

The above relations give optimal stability conditions and balance surface energy terms with shrinking ones. According to Figure 4, the number of binding segments is limited. In the calculations we imposed some constraints and assumed weak interactions energies among PEO and NPs. This is in agreement with the accepted behavior of medium-size homo-polymers [56], where the number of bound segments is limited.
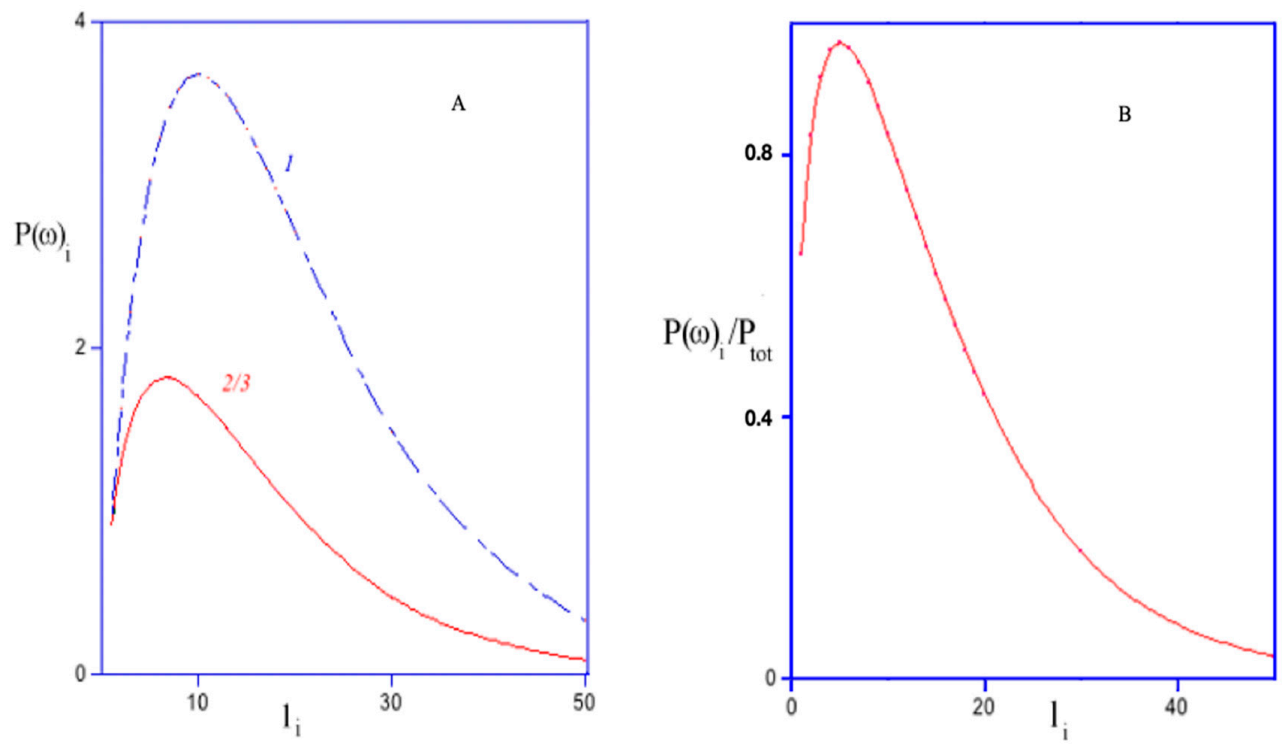

Figure 4. (A). Binding probability, $P(\Omega)_{i}$, in arbitrary units, vs. the number of polymer units in the main chain, $l_{i}$, for $k_{i}$ terms equal to $2 / 3$, red, and 1.0 , blue, at $25.0^{\circ}$. Data were calculated for PEO binding onto $\mathrm{SiO}_{2}$. The number of segments in PEO chain is 50; the NP's diameter is $200 \mathrm{~nm}$. (B). Normalized plot of $P(\Omega)_{i} / P_{\text {tot }}$ vs. $l_{i}$, calculated assuming $k_{i}$ to be proportional to $\sqrt{ } l_{i}$. The behavior conforms to common knowledge on the binding efficiency of small-medium length polymers. See the text for more details.

According to the calculations, less than 15 units over 50 are substantially bound. This implies a large number of protruding units and an extended corona. Even if not evident from the above equations, the hydration energy of polymer protruding parts is large.

Estimates of energy terms reported in Equations (10) and (11) are given below. As a consequence of $\mathrm{PEO}$ adsorption onto $\mathrm{SiO}_{2}$ and of the number of bound $\mathrm{EO}$ units calculated by the distribution function, the contribution due to $w$, i.e., to its transfer from the bulk to the NP surface, is 10-12 $\mathrm{kcal} \mathrm{mol}^{-1}$. The $\pi$ term is hardly estimated, but it is close to the osmotic pressure that concentrated polymer solutions exert on the NP surface: about $1 \mathrm{kcal} \mathrm{mol}^{-1}$. Terms due to polymer-solvent interactions, not present in the equations, may be significant. Therefore, even neglecting rotational, $\eta$, and dehydration terms, a substantial wrapping energy is obtained. Such contribution ensures an efficient coverage.

\subsection{Some Details on the Preparation of Hybrid Particles}

A bunch of combinations among NPs and surface modifiers is possible. Starting from the quite popular $\mathrm{SiO}_{2}$, intended as a reference system, we define several classes, which were partitioned in sub-categories. Sometimes, it is hard to distinguish one from another 
mode, since differences are subtle and involve modifications in either NPs nature, polymers and/or both.

\subsubsection{Nanoparticles}

Tentatively, NPs with organic/inorganic cores can be divided in the following categories:

(1) Raw NPs. They remain as such until non-covalent coverage occurs through the adsorption of a polymer in a bad solvent $[57,58]$. This is the case of $\mathrm{SiO}_{2}$ coverage which was the first attempt used to date [59]. This procedure has severe drawbacks due to the difficulty to eliminate the solvent.

(2) Surface-charged NPs are modified by modulating the medium $p H$, to ensure ad hoc surface charge density $[60,61]$. Dissolution in proper solvents favors such a step. This process is required to induce the adsorption of ionic polymers [62].

(3) H-M NPs. The process implies using as a preliminary step the procedures indicated in Point (2) [63-66]. Reaction with fatty acids, alkyl-amines, and/or long-chain alcohols leads to the formation of $H-M$ entities; see Figure 5. These are capable of later binding proper polymers. Such particles are sticky to the touch and are nucleation sites for the adsorption of hydrophobic molecules. In some sense, they act in analogy to oil droplets, as to the binding of hydrophobic moieties is concerned. Similar considerations apply if species binding thereon are surfactants.

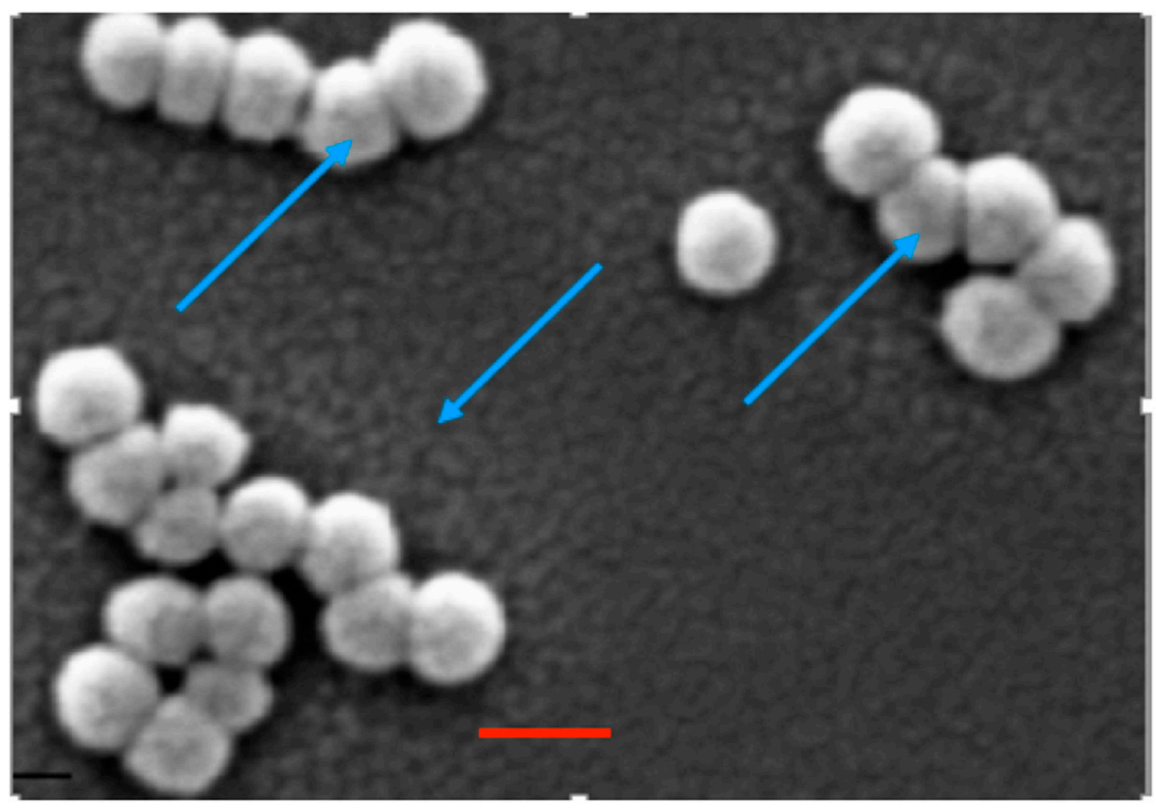

Figure 5. Nanoparticles of $\mathrm{SiO}_{2}\left(220 \mathrm{~nm}\right.$ in size) onto which $\mathrm{C}_{18} \mathrm{OH}$ was adsorbed. $N P$ s were dissolved in $\mathrm{EtOH}$, reacted, dried, repeatedly washed in organic solvents, and kept in DMF until use. NPs stickiness, when they are left on air for some hours, is evident, as indicated by blue arrows. The inter-particle regions have strong similarity with details met when cells join together, or there is mitosis during the partition in two daughter cells. The red bar size is $300 \mathrm{~nm}$ long. For more details, see Ref. [59].

(4) Biopolymer-coated NPs. They share substantial similarities in common with those mentioned in Point 2), and significant differences, too. Such differences are due to the necessary chemical or structural modifications required to allow an effective biopolymer binding. Typical examples are those dealing with $\mathrm{pH}$ changes inducing in proteins significant charge density or denaturation. Both favor the onset of extended hydrophobic moieties. It is difficult to separate one mode from the other, as in $\mathrm{pH}$-dependent albumin binding onto synthetic vesicles [67]. Even more exotic is the necessity to get single stranded DNA, which is capable of binding onto carbon nanotubes only if transformed in a less rigid form than the native one $[68,69]$. 
(5) Fully hydrophobic NPs are particles with polystyrene, PS, or poly-methyl methacrylate, PMMA, as inner cores [70,71]. They are manipulated in such a way to allow a permanent binding. This process occurs via covalent functionality procedures. The inherent drawbacks arise from using toxic reactants.

(6) Metal-based nanoparticles. These can be made of metals or metal oxides. Such entities can be functionally modified as indicated above. Sometimes, it is necessary to form layered entities, in preparing NP-based super-capacitors, for instance [72].

(7) Surfactant-coated NPs. The latter are of ancillary use, due to a surfactant exchange with the bulk. The mentioned phenomenon is controlled by the adsorption/desorption to and from the NP surface and is not different from that occurring at fluid surfaces. It is counteracted by adding electrolytes [73] to reduce the surface charge density, eventually by adding alcohols, or other co-surfactants. The addition of polymers (but also proteins) gives polymer-surfactant complexes [74], which are located on the NP surfaces in question.

(8) Vesicles. Such matrices find substantial similarities with cells and thus are used in biomedical applications. The significant biomimetic character renders them compatible with most biological tissues $[75,76]$ and allows for their use in biomedicine and transfection technologies. Surface functionality occurs in the same way as in nature. Promising are synthetic vesicles composed by lipids or surfactant mixtures, bearing oppositely charged polar heads [77-79]. Such systems, prepared by mixing the two species in non-stoichiometric ratios (in terms of charge, or mole numbers), are easily modulated in size and surface charge density; see Figure 6 [80]. The resulting entities can be either positively or negatively charged, depending on which surfactant is in excess. An example is the system made of SDS (Sodium Dodecylsulfate) and CTAB (Cetyl-trimethylammonium Bromide). When the ratio among the two is unity, vesicle sizes diverge and lamellar entities do form. Cat-anionic vesicles, $C A T-A N$, adsorb cationic or anionic bio-polymers through electrostatic, $v d W$, or other physical forces, including combinations thereof. As inferred from that tentative list, the number of possible combinations is extremely rich and diversified. This fact gives to formulators a wide bunch of technological possibilities to be experienced.

\subsubsection{Polymers}

Polymers and bio-polymers belong to an enormously wide category. They differ in polarity, length, size dispersivity index, number of protruding units, stiffness vs. elasticity, etc. Homo-, or block co-polymers can be used. Length is crucial in determining the adhesion probability, as also does the presence of ionic/nonionic blocks in the main chain. A pertinent case is that of PEO-poly-L-lysine hydro-bromide, which is widely used in recent years [36,81]. Bio-polymers may be proteins, their hydrolyzed, synthetic polypeptides, polysaccharides (raw or functionally modified), DNA, or RNA. The same applies to polymer-surfactant adducts. There is also the less commonly used possibility that a particle type is surface covered by another, differing in physical nature, size, and shape from the host one. That possibility ensures the possible bio-mimicry of hybrids with cells and viruses.

\subsection{Size and Shapes}

The success of hybrid preparation depends on the required features, which are expressed in terms of shapes and chemical composition. Sizes span from a few nm upwards, when shapes are spheroidal, cylindrical, plate-like, star-like [80], and so forth. In case of composite NPs, the sub-units may combine in non-canonical geometries, depending on the domain's composition. The resulting effects may also be controlled by charge accumulation on the protruding $N P^{\prime}$ s edges or on curved domains [82]; see Figure 7 . Note that what we define as "smooth" are winding and twisting on an atomic scale level; that is the reason for a substantial charge accumulation on some colloid particles. This is true for inorganic or polymer-based NPs. However, bio-based particles that bind more entities on their surfaces, similar to cells and viruses, operate on the same grounds. 


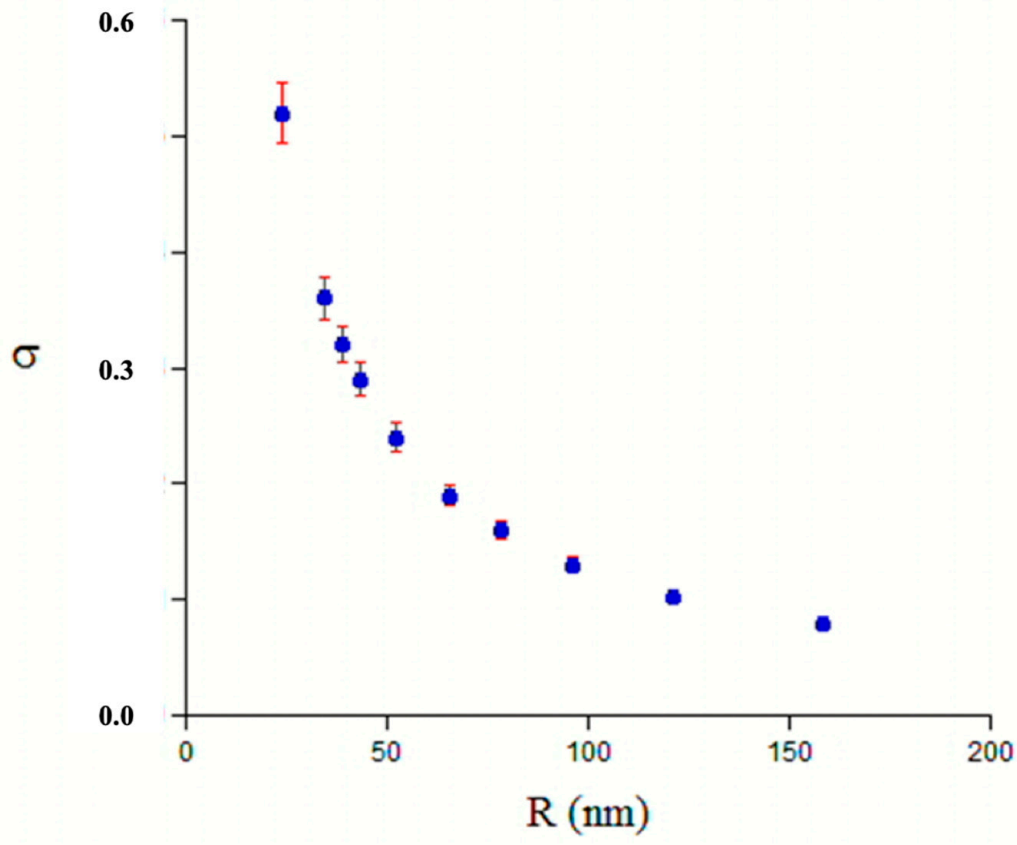

Figure 6. Relation between surface charge density, $\sigma$, in $Q \mathrm{~cm}^{-2}$, and average vesicle radius, $R$ $(\mathrm{nm})$, for cat-anionic vesicles made of unequal amounts of SDS and CTAB. The solution contains $6.2 \times 10^{-3} \mathrm{~mol} \mathrm{~kg}^{-1}$, at $25.0{ }^{\circ} \mathrm{C}$, with ionic species in non-stoichiometric ratios. What is reported here refers to a CTAB-rich vesicle. As expected, the surface charge density decreases with the SDS mole ratio in the mixture. The reported behavior is tentatively described by a relation keeping the form $\sigma R=K$. A specular behavior is met when the species in excess is SDS and CTAB is added. In that case, obviously, $\sigma$ is negative.

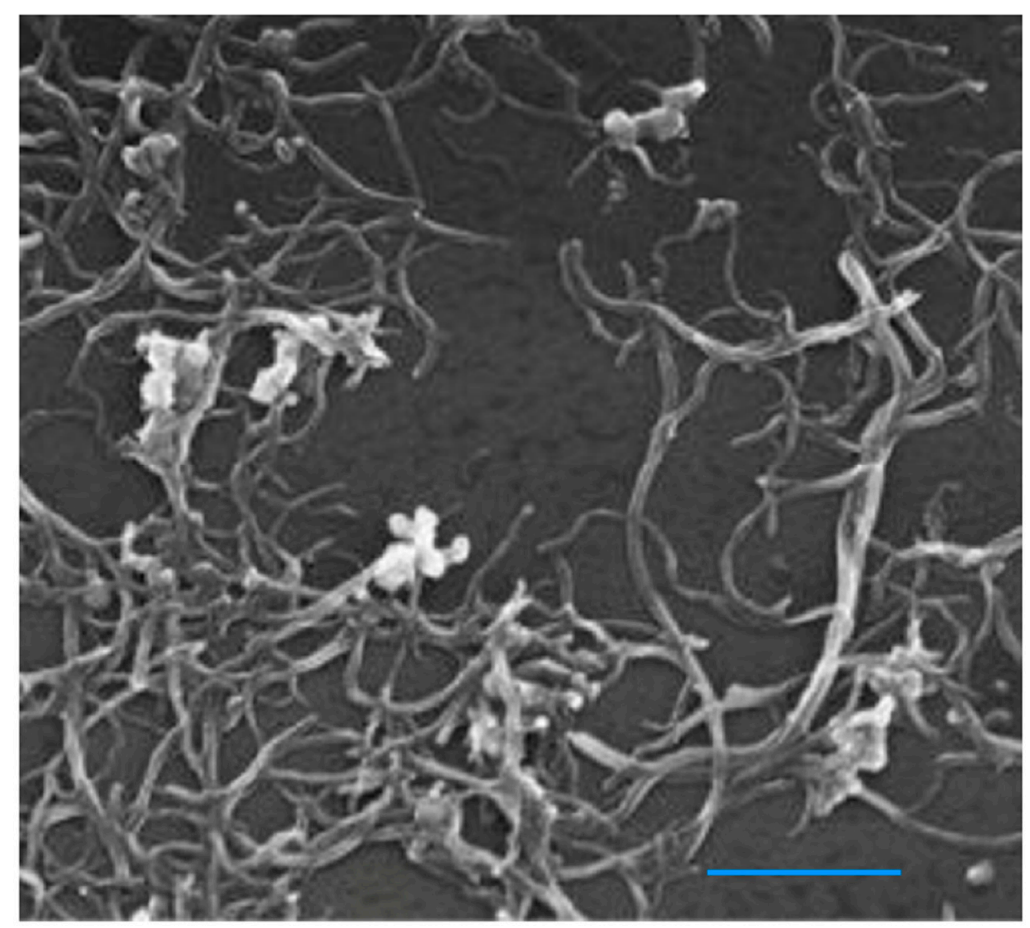

Figure 7. Adsorption of $\mathrm{TiO}_{2}$ nanoparticles, directly flourishing onto the edges and curvatures of single-strand DNA carbon nanotubes, as flowers do onto the branches of the Judas tree, (Cercis Siliquastrum). The blue bar size length is $250 \mathrm{~nm}$. Redrawn from Reference [83]. 


\section{Materials Preparation}

\subsection{Preparation Procedures for Getting Hybrids}

According to what was previously stated, a number of preparation pathways is possible. This is due to the wide number of NPs and of adsorbing species that are actually required. We indicate below the main categories, each characterized by proper reaction modes. These include covalent, non-specific adsorption, and electrostatic interactions. The pertinent energies span from a few to over $100 \mathrm{kcal} \mathrm{mol}^{-1}$. It is worth noticing, perhaps, that the term "weak interaction forces" refers to one binding unit, whereas many of those do effectively take place on the same particle. In addition, the insertion of one functional group may favor more ones because of the overlapping of many energy terms. It is also relevant to point out that weak adsorption forces imply interactions among close polymer units that protrude outward the bulk, not to mention the ubiquitous dehydration effects.

There are many possible pathways to proceed along these lines. The most pertinent ones are the following:

(a) Through covalent linkage among NPs and polymers. Both are endowed with new functionalities in such a way to ensure an efficient, and permanent, chemical bond. Thus, NPs will contain reactive surface groups. The most common are alcohols, amines, acyl chlorides, or double $\mathrm{C}=\mathrm{C}$ bonds pending on the NPs surface. Complementary groups are located at one end of the polymer to be linked. Eventually, the use of catalysts shall be required on that purpose. One-pot building procedures are by far preferred.

(b) Through surface adsorption. This non-specific pathway requires the adhesion of a significant polymer portion on the NP surface, according to what was mentioned in Section 3.2. The energies that are required for the binding of a single unit (such as an ethylene oxide one) are moderate, but many of those effectively take place. Other contributions mentioned above are also relevant. The process is favored by dialysis, by modifying the solvent nature, or the working temperature.

(c) Electrostatic in nature. This latter modality is twofold in nature. In the foamier case, it is related to the binding of ionic polymer moieties onto oppositely charged NPs. A typical example is met in the binding of PEO-poly-L-lysine hydro-bromide block copolymer onto charged particles; the effect is often concomitant to the dehydration of either polymer and NP moieties, and as a rule, it is entropically favored. In the second one, oppositely charged polymer domains tend to pack, thus giving compact coronas. The latter eventuality has been extensively described in important contributions due to Prof. Dobrynin $[84,85]$.

It is possible to have the combination among two, or more, of the mentioned modes, as indicated above. However, it must be considered that the relative weight of these contributions can be quite diverse.

\subsection{Optimization Procedures}

Hybrids suffer from being rather poly-disperse in size and substitution degree. In most technological purposes, this is not a serious fault. However, the situation can be problematic in case of applications for advanced biomedical purposes. Imagine, for instance, that a given hybrid is intended to bind a specific site. This requires, in sequence, the need to have proper length of the protruding units and/or the right functionality and the final edge of the polymer chain. In cases in which this would not hold, the key-lock strategy will surely lose its effective significance. This fact requires a due selection of the protruding units, which can be obtained by "living" polymerization pathways [86], in such a way that the species to be surface anchored retain a proper length.

The same holds for the strategies in use to get finely size mono-disperse particles. It is well known, in this regard, that optimizing the reactive conditions ensures the possibility to get finely mono-disperse entities, depending on the amount of reactants, on the working conditions, and on the preparation pathways, including time control. Pertinent examples deal with the preparation of $\mathrm{SiO}_{2}$ or $\mathrm{TiO}_{2}$, nanoparticles in bottom-up strategies [87]. Depending on what is stated above, the NPs can be effectively size mono-dispersed. 
In all cases reported above, one must avoid polymer depletion from the NP's surfaces. Such an effect has been described in theoretical and experimental approaches [88,89], and it can be met in all instances where surface coverage is needed $[90,91]$. As such, it occurs in polymer and/or surfactant stabilized systems; it finds origin in the presence of unbalanced osmotic gradients between entities located on the surface and the bulk. It is often concomitant to a phase separation of particles that are no longer surface stabilized. Therefore, it is obvious that it must be counteracted or controlled. This can be done by changing the solvent, using polymer (surfactant) blends in place of a single species, adding electrolytes, or modulating the temperature.

\section{Applications}

If we look at the increase in number of articles, reviews, and patents keeping the term hybrid in their titles or in the manuscripts, it is evident that a critical, drastic, increase in such numbers has been reached in the last few years. Some contributions focus on the potentialities offered by new materials, although a cogent analysis of their effective applicability is far to be completed. Anyhow, successful results have been obtained in many fields. The list below is far from being conclusive and only indicates the items that we personally suppose to be the most promising in a close future. Intentionally, we did not consider in the list a wide bunch of patents that appeared in the last few years. To mind but a few selected ones, let us mention significant results in the following areas:

\subsection{Heterogeneous Catalysis}

These include a variety of interesting subjects, such as CNT-polymer dendrimerlike hybrids, thanks to the contribution of Prato et al. [92], hybrid nanoparticles made of metal/metal oxide cores [93,94], porous polymer sponges containing metals [95], goldgraphene hybrids [96], and so forth.

\subsection{Wastewater Treatment}

Noteworthy are contributions that appeared in articles and in a series on water pollution and bioremediation technologies [97,98].

\subsection{Molecular Medicine}

Given the possibility to get tailored species, mostly in terms of surface functionalities, release capacity, and bio-compatibility, many have tried getting formulations capable of operating at the gut level [99], gene silencing [100], bone tissue regeneration [101-103], preparing devices [104] and/or decorating NPs with human stem cells [105], and anticancer therapy [106], as well. We do not know exactly how efficient the mentioned formulations are compared to canonical ones, but it expected that their safe use is close to be effective in vivo.

\subsection{Food Sciences}

This field of research is at an advanced state, due to the fact that many food prepares contain true hybrid nanoparticles. Think to the impressive amount of work, dating back to some thousand years ago and focusing on the cheese-making sequences. Today, efforts proceed on the same line, trying to get products with superior quality in terms of safety and with significant yields, too. English [107], Italian [108], and Dutch [109] universities are worldwide recognized for taking care of the above field and to go ahead with a series of important initiatives in the field of colloid-based formulations used in the food industry.

\subsection{Electronics and Micro-Devices}

The reasons for using $N P$-based hybrids arise from the combination of properties inherent to the nanoparticles that form the resulting objects. The high surface to volume ratio is one of the most relevant; associated is a relative low density compared to the objects in mass. It is worth noticing the easy possibility to model them in the desired 
shape. More substantial is the fact that highly porous matter has an eminent capacity to adsorb gases or target molecules. Finally, the possibility to form layered entities ensures that the resulting objects have the possibility of getting entities characterized by a high charge storage capacity. This fact ensures the possibility of getting high quality supercapacitors [110]. Relevant too is the possibility of getting a coating with the selected properties as a significant hydrophobic nature [111]. As to the applications in technology, let us remind, among many others, a safe and possible use for heat transfer on large scale [112]. Many other applications are possible.

\section{Conclusions}

It is shown here that the concept of hybrid is extremely useful in understanding the features of modern colloid composites and allows one extending to that field almost everything we historically know from literature, art, and nature. The concept can be extended to include a lot of objects that we know not to be compatible in logical grounds, but it can be mixed in such a way to get impressions much stronger than those pertinent to the single components. It is what we know from classical art and literature when the concepts of "horrible" and "phantasmic" were conjugated each other to become unusual, disquieting, and fascinating in the same time. This is the reason for the similarity that synthetic hybrids share with ones met in classical literature, as mentioned above.

In some aspects, the concept hybrid is a direct consequence of the second principle of thermodynamics when applied to items that seem to be incompatible at a first view. Note that the formation of hybrids is almost always concomitant with the significant dehydration of the units participating to such processes where entropy contributions may be significant.

In terms of prime principles, mixing chemicals, although poorly compatible with each other, is not much different from joining together objects whose features seem conflicting. More points to be put in evidence are the strong biomimicry of hybrids that are obtained from tailored experiments with those met in selected biological systems. For example, think to the steric stabilization of casein micelles [113]. Its presence avoids the coagulation of the mentioned entities, until proteolytic enzymes cut the polypeptide moieties facing outward casein. It is evident that to proceed along these lines, significant modeling and dedicated experimental efforts are needed to get the desired results.

Author Contributions: Conceptualization of the manuscript is due to both authors. They took care of the biological (G.R.) and chemical (C.L.M.) parts, when all cultural aspects in the introduction were jointly developed. Both authors have read and agreed to the published version of the manuscript.

Funding: This research was funded by Sapienza University, through grant number 1937/2019.

Data Availability Statement: Not applicable in a review. The readers may refer to the original cited works.

Acknowledgments: We wish to thank G.A. Ranieri, formerly at Calabria University, and L. Suber, formerly at Natl. Res. Council, for useful suggestions on some points in the manuscript.

Conflicts of Interest: The authors declare that conflict of interest does not exist.

\section{Abbreviations}

N.B. The word "Taxonomy" indicates the latin definition of animals and plant species as compared to their common use name.

\section{References and Notes}

1. Posthumus, L. Hybrid Monsters in the Classical World. The Nature and Function of Hybrid Monsters in Greek Mythology, Literature and Art. Ph.D. Thesis, University of Stellenbosch, Stellenbosch, South Africa, 2011.

2. Morrison, E. (Ed.) Book of Beasts: The Bestiary in the Medieval World; Getty Publications: New York, NY, USA, 1989.

3. Cox, L.R. Thoughts on the classification of the Gastropoda. J. Molluscan Stud. 1960, 33, 239-261. 
4. Piperno, D.R.; Ranere, A.J.; Holst, I.; Iriarte, J.; Dickau, R. Starch grain and phytolith evidence for early ninth millennium B.P. maize from the Central Balsas River Valley, Mexico. Proc. Natl. Acad. Sci. USA 2009, 106, 5019-5024. [CrossRef] [PubMed]

5. Belmonte-Ureña, L.J.; Garrido-Cardenas, J.A.; Camacho-Ferre, F. Analysis of world research on grafting in horticultural plants. HortScience 2019, 55, 112-120. [CrossRef]

6. der Manuelian, P. Egypt: The World of the Pharaohs; Könemann: Cologne, Germany, 1998; p. 381.

7. Nicholson, P.T. Ancient Egyptian Materials and Technology; Cambridge Univ. Press: Cambridge, UK, 2000; p. 409.

8. Clutton-Brock, J. Domesticated Animals from Early Times; Heinemann: London, UK, 1981; p. 145.

9. Davison, A.; Birks, J.D.S.; Griffiths, H.I.; Kitchener, A.C.; Biggins, D.; Butlin, R.K. Hybridization and the phylogenetic relationship between polecats and domestic ferrets in Britain. Biol. Conserv. 1999, 87, 155-161. [CrossRef]

10. Thomson, A.P.D. A history of the ferret. J. Hist. Med. Allied Sci. 1951, 6, 471-480. [CrossRef]

11. Zhang, F.; Wen, Y.; Guo, X. CRISPR/Cas9 for genome editing: Progress, implications and challenges. Hum. Mol. Genet. 2014, 23, 40-46. [CrossRef]

12. Dawkins, R. The Ancestor's Tale. The Dawn of Evolution; Mariner Books, Eamon Dolan Book; Houghton Mifflin Hartcourt: Boston, MA, USA; New York, NY, USA, 2016.

13. Mahla, R.S. Stem cells applications in regenerative medicine and disease therapeutic. Intern. J. Cell Biol. 2016, $2016,6940283$. [CrossRef] [PubMed]

14. Gourzones-Dmitriev, C.; Kassambara, A.; Sahota, S.; Rème, T.; Moreaux, J.; Bourquard, P.; Hose, D.; Pasero, P.; Constantinou, A.; Klein, B. DNA repair pathways in human multiple myeloma. Role in oncogenesis and potential targets for treatment. Cell Cycle 2013, 12, 2760-2773. [CrossRef] [PubMed]

15. von Leibniz, G.W. New Essays on Human Understanding; Langley, P., Ed.; Cambridge University Press: Cambridge, UK, 1996; Wiener III.6 (part).

16. Linnaeus, C. Systema Naturae, Sive Regna tria Naturae Systematice Proposita per Classes, Ordines, Genera, E Species; Haak: Leiden, The Netherlands, 1735; pp. 1-12.

17. Rocke, A.J. Image and Reality: Kekulé, Kopp, and the Scientific Imagination; The University of Chicago Press: Chicago, IL, USA; New York, NY, USA, 2010.

18. Pauling, L. The nature of the chemical bond. Application of results obtained from the quantum mechanics and from a theory of paramagnetic susceptibility to the structure of molecules. J. Am. Chem. Soc. 1931, 53, 1367-1400. [CrossRef]

19. Pauling, L. The nature of the chemical bond. II. The one-electron bond and the three-electron bond. J. Am. Chem. Soc. 1931, 53, 3225-3237. [CrossRef]

20. Pauling, L. The nature of the chemical bond. III. The transition from one extreme bond type to another. J. Am. Chem. Soc. 1932, 54, 988-1003. [CrossRef]

21. Pauling, L. The nature of the chemical bond. IV. The energy of single bonds and the relative electronegativity of atoms. J. Am. Chem. Soc. 1932, 54, 3570-3582. [CrossRef]

22. Pauling, L. The nature of the chemical bond-1992. J. Chem. Ed. 1992, 69, 519-521. [CrossRef]

23. Zott, R. Friedrich Wilhelm Ostwald (1853-1932), Now 150 years young. Angew. Chem. Int. Ed. 2003, 42, 3990-3995. [CrossRef] [PubMed]

24. Ertl, G. Wilhelm Ostwald: Founder of physical chemistry and nobel laureate 1909. Angew. Chem. Intern. Ed. 2009, 48, 6600-6606. [CrossRef] [PubMed]

25. McBain, J.W.; and colleagues published their first article on Ber., 1910, 43, 321. Others appeared on Trans. Chem. Soc. 1911, 99, 191; Z. Physik. Chem. 1911, 75, 191; ibid., 1912, 76, 179; Kolloid Zh. 1913, 13, 56; and in 1914. N.B. Due to the 1st world war, some were rewritten, or reissued, after 1919.

26. N.B. In an international congress Wilhelm Ostwald, an outstanding physical and colloid chemist, Nobel Graduate in Chemistry 1909, and excellent polemicist, vividly rejected the concept of "colloidal electrolytes" with the vivid sentence "Paradox, McBain!".

27. McBain, J.W.; Salmon, C.S. Colloidal electrolytes. Soap solutions and their constitution. Proc. R. Soc. A 1920, 97, 44-65. [CrossRef]

28. Murray, R.C.; Hartley, G.S. Equilibrium between micelles and simple ions, with particular reference to the solubility of long-chain salts. Trans. Faraday Soc. 1935, 31, 183-189. [CrossRef]

29. Ringsdorf, H. Hermann Staudinger and the future of polymer research jubilees-beloved occasions for cultural piety. Angew. Chem. Intern. Ed. 2004, 43, 1064-1076. [CrossRef]

30. Gunay, K.A.; Theato, P.; Klok, H.-A. Standing on the shoulders of Herman Staudinger. Post-Polymerization modification from past to present. J. Polym. Sci. A Polym. Chem. 2013, 51, 1-28. [CrossRef]

31. N.B. Until the 20's of the XX century it was firmly supposed that polymers and association colloids substantially differed each from the other in physical nature and properties. At the end of that decade most scientists became conscious of the fact that both belong to the category of colloids, either intrinsic or association ones. They sense nearly the same forces, and can be investigated on similar grounds, as suggested from a lot of experimental evidence.

32. Feynman, R.P. There's plenty of room at the bottom. Engin. Sci. 1960, 2, 1-11.

33. Li, A.; Kung, L.; Kam, J.S.; Hovis, S.J.; Boxer, S.G. Patterning hybrid surfaces of proteins and supported lipid bilayers. Langmuir 2000, 16, 6773-6776.

34. Gupta, M.K.; Srivastava, R.K. Mechanical properties of hybrid fibers-reinforced polymer composite: A review. Polym. Plast. Technol. Eng. 2016, 55, 226-242. [CrossRef] 
35. Mallick, K.; Witcomb, M.J.; Scurrell, M.S. Polymer stabilized silver nanoparticles: A photochemical synthesis route. J. Mater. Sci. 2004, 39, 4459-4463. [CrossRef]

36. Louguet, S.; Kumar, A.C.; Guidolin, N.; Sigaud, G.; Duguet, E.; Lecommandoux, S.; Schatz, C. Control of the PEO chain conformation on nanoparticles by adsorption of PEO-block-Poly(L-lysine) copolymers and its significance on colloidal stability and protein repellency. Langmuir 2011, 27, 12891-12901. [CrossRef] [PubMed]

37. Tanford, C. The Hydrophobic Effect: Formation of Micelles and Biological Membranes, 2nd ed.; Wiley: New York, NY, USA, 1980.

38. Rance, G.A.; Marsh, D.H.; Bourne, S.J.; Reade, T.J.; Khlobystov, A.N. van der Waals interactions between nanotubes and nanoparticles for controlled assembly of composite nanostructures. ACS Nano 2010, 4, 4920-4928. [CrossRef]

39. Shi, X.; Cassagneau, T.; Caruso, F. Electrostatic interactions between polyelectrolytes and a titania precursor: Thin film and solution studies. Langmuir 2002, 18, 904-910. [CrossRef]

40. Quaroni, L.; Chumanov, G. Preparation of polymer-coated functionalized silver nanoparticles. J. Am. Chem. Soc. 1999, 121, 10642-10643. [CrossRef]

41. Gregory, J.; Barany, S. Adsorption and flocculation by polymers and polymer mixtures. Adv. Colloid Interface Sci. 2011, 169, 1-12 [CrossRef]

42. Veronovski, N.; Andreozzi, P.; la Mesa, C.; Sfiligoj-Smole, M.; Ribitsch, V. Use of gemini surfactants to stabilize TiO 2 P-25 colloidal dispersions. Colloid Polym. Sci. 2010, 288, 387-394. [CrossRef]

43. Flory, P.J. Statistical mechanics of swelling of network structures. J. Chem. Phys. 1950, 18, 108-114. [CrossRef]

44. Flory, P.J. Statistical Mechanics of Chain Molecules; Inter-science Publishers: Geneva, Switzerland, 1969.

45. Tallury, S.S.; Pasquinelli, M.A. Molecular dynamics simulations of flexible polymer chains wrapping single-walled carbon nanotubes. J. Phys. Chem. B 2010, 114, 4122-4129. [CrossRef] [PubMed]

46. Baskaran, D.; Mays, J.W.; Bratcher, M.S. Noncovalent and nonspecific molecular interactions of polymers with multiwalled carbon nanotubes. Chem. Mater. 2005, 17, 3389-3397. [CrossRef]

47. Chen, R.J.; Zhang, Y.; Wang, D.; Dai, H. Noncovalent sidewall functionalization of single-walled carbon nanotubes for protein immobilization. J. Am. Chem. Soc. 2001, 123, 3838-3839. [CrossRef] [PubMed]

48. Gittins, D.I.; Caruso, F. Tailoring the polyelectrolyte coating of metal nanoparticles. J. Phys. Chem. B 2001, $105,6846-6852$. [CrossRef]

49. Liu, Y.; Jiang, W.; Li, S.; Li, F. Electrostatic self-assembly of $\mathrm{Fe}_{3} \mathrm{O}_{4}$ nanoparticles on carbon nanotubes. Appl. Surf. Sci. 2009, 255, 7999-8002. [CrossRef]

50. Liu, H.; Lv, M.; Deng, B.; Li, J.; Yu, M.; Huang, Q.; Fan, C. Laundering durable antibacterial cotton fabrics grafted with pomegranate-shaped polymer wrapped in silver nanoparticle aggregations. Sci. Rep. 2014, 4, 5920. [CrossRef] [PubMed]

51. Yoo, D.Y.; Tu, N.D.K.; Lee, S.J.; Lee, E.; Jeon, S.-R.; Hwang, S.; Lim, H.S.; Kim, J.K.; Ju, B.K.; Kim, H.; et al. Graphene oxide nanosheet wrapped white-emissive conjugated polymer nanoparticles. ACS Nano 2014, 8, 4248-4256. [CrossRef]

52. Chapman, R.; Stenzel, M.H. All wrapped up: Stabilization of enzymes within single enzyme nanoparticles. J. Am. Chem. Soc. 2019, 141, 2754-2769. [CrossRef]

53. Gittins, D.I.; Caruso, F. Multilayered polymer nanocapsules derived from gold nanoparticle templates. Adv. Mater. 2000, 12, 1947-1949. [CrossRef]

54. Vold, R.D.; Vold, M.J. Colloid and Interface Chemistry; Addison-Wesley: Reading, UK, 1983; Chapter IV.

55. Adamson, A.W. Physical Chemistry of Surfaces, 5th ed.; Wiley: New York, NY, USA, 1990; Chapter XI.

56. Nikas, Y.J.; Blankschtein, D. Complexation of nonionic polymers and surfactants in dilute aqueous solutions. Langmuir 1994, 10, 3512-3528. [CrossRef]

57. Israelachvili, J.N. Intermolecular and Surface Forces, 3rd ed.; Acad. Press: Waltham, MA, USA, 2011; Chapter X.

58. de Gennes, P.G. Scaling Concepts in Polymer Physics; Cornell University Press: Ithaca, NY, USA, 1979.

59. Andreozzi, P.; La Mesa, C.; Masci, G.; Suber, L. Formation and Physicochemical Characterization of Silica-Based Blackberry-like Nanoparticles Capped by Polysaccharides. J. Phys. Chem. C 2007, 111, 18004-18009. [CrossRef]

60. Robertson, C.G.; Roland, C.M. Glass transition and interfacial segmental dynamics in polymer-particle composites. Rubber Chem. 2008, 81, 506-522. [CrossRef]

61. Stornes, M.; Linse, P.; Dias, R.S. Monte Carlo simulations of complexation between weak polyelectrolytes and a charged nanoparticle. Influence of polyelectrolyte chain length and concentration. Macromolecules 2017, 50, 5978-5988. [CrossRef]

62. Wu, S.-H.; Mou, C.-Y.; Lin, H.-P. Synthesis of mesoporous silica nanoparticles. Chem. Soc. Rev. 2013, 42, 3862-3875. [CrossRef]

63. Wang, L.; Zhao, W.; Tan, W. Bioconjugated silica nanoparticles: Development and applications. Nano Res. 2008, 1, 99-115. [CrossRef]

64. Koutsos, V.; van der Vegte, E.W.; Pelletier, E.; Stamouli, A.; Hadziioannou, G. Structure of chemically end-grafted polymer chains studied by scanning force microscopy in bad-solvent conditions. Macromolecules 1997, 30, 4719-4726. [CrossRef]

65. Sarkar, B.; Venugopal, V.; Tsianou, M.; Alexandridis, P. Adsorption of Pluronic block copolymers on silica nanoparticles. Colloids Surf. A Physicochem. Engin. Asp. 2013, 422, 155-164. [CrossRef]

66. Gan, Q.; Wang, T.; Cochrane, C.; McCarron, P. Modulation of surface charge, particle size and morphological properties of chitosan-TPP nanoparticles intended for gene delivery. Colloids Surf. B Biointerfaces 2005, 44, 65-73. [CrossRef]

67. Pucci, C.; Scipioni, A.; la Mesa, C. Albumin binding onto synthetic vesicles. Soft Matter 2012, 8, 9669-9675. [CrossRef] 
68. Badaire, S.; Zakri, C.; Maugey, M.; Derre, A.; Barisci, J.N.; Wallace, G.; Poulin, P. Liquid crystals of DNA-stabilized carbon nanotubes. Adv. Mater. 2005, 17, 1673-1676. [CrossRef]

69. Tardani, F.; la Mesa, C.; Poulin, P.; Maugey, M. Phase behavior of DNA-based dispersions containing carbon nanotubes: Effects of added polymers and ionic strength on excluded volume. J. Phys. Chem. C 2012, 116, 9888-9894. [CrossRef]

70. Kockmanna, A.; Porsiela, J.C.; Saadata, R.; Garnweitner, G. Impact of nanoparticle surface modification on the mechanical properties of polystyrene-based nanocomposites. RSC Adv. 2018, 8, 11109-11118. [CrossRef]

71. Ali, U.; Karim, K.J.B.A.; Buang, N.A. A review of the properties and applications of poly (Methyl Methacrylate) (PMMA). Polym. Rev. 2015, 55, 678-705. [CrossRef]

72. Xu, F.; Cai, R.; Zeng, Q.; Zou, C.; Wu, D.; Li, F.; Lu, X.; Liang, Y.; Fu, R. Fast ion transport and high capacitance of polystyrene-based hierarchical porous carbon electrode material for super-capacitors. J. Mater. Chem. 2011, 21, 1970-1976. [CrossRef]

73. van Os, N.M.; Haak, J.R.; Rupert, L.A.M. Physico-Chemical Properties of Selected Anionic, Cationic and Nonionic Surfactants; Elsevier: Amsterdam, The Netherlands, 1993.

74. La Mesa, C. Polymer-Surfactant and protein-surfactant interactions. J. Colloid Interface Sci. 2005, 268, 148-157. [CrossRef]

75. Bonincontro, A.; Falivene, M.; la Mesa, C.; Risuleo, G.; Pena, M.R. Dynamics of DNA adsorption on and release from SDS-DDAB Cat-Anionic vesicles: A multitechnique study. Langmuir 2008, 24, 1973-1978. [CrossRef]

76. Aiello, C.; Andreozzi, P.; la Mesa, C.; Risuleo, G. Biological activity of SDS-CTAB cat-anionic vesicles in cultured cells and assessment of their cytotoxicity ending in apoptosis. Colloids Surf. B Biointerfaces 2010, 78, 149-154. [CrossRef] [PubMed]

77. Mal, A.; Bag, S.; Ghosh, S.; Moulik, S.P. Physicochemistry of CTAB-SDS interacted catanionic micelle-vesicle forming system: An extended exploration. Colloids Surf. A Physicochem. Engin. Asp. 2018, 553, 633-644. [CrossRef]

78. Milchovich, G.; Antunes, F.E.; Grassi, M.; Asaro, F. Soft nano-onions: A dynamic overview onto catanionic vesicles temperaturedriven transition. Int. J. Mol. Sci. 2020, 21, 6804. [CrossRef] [PubMed]

79. Lozano, N.; Pérez, L.; Pons, R.; Pinazo, A. Diacyl glycerol arginine-based surfactants: Biological and physicochemical properties of catanionic formulations. Amino Acids 2011, 40, 721-729. [CrossRef]

80. Barbetta, A.; Pucci, C.; Tardani, F.; Andreozzi, P.; la Mesa, C. Size and charge modulation of surfactant-based vesicles. J. Phys. Chem. B 2011, 115, 12751-12758. [CrossRef]

81. Louguet, S.; Kumar, A.C.; Sigaud, G.; Duguet, E.; Lecommandoux, S.; Schatz, C. A physico-chemical investigation of poly(ethylene oxide)-block-poly(1-lysine) copolymer adsorption onto silica nanoparticles. J. Colloid Interface Sci. 2011, 359, 413-422. [CrossRef] [PubMed]

82. Suber, L.; Plunkett, W.R. Formation mechanism of silver nanoparticle 1D microstructures and their hierarchical assembly into 3D superstructures. Nanoscale 2010, 2, 128-133. [CrossRef] [PubMed]

83. Romio, M.; La Mesa, C. Hybrid nano-composites made of ss-DNA/wrapped carbon nanotubes and titania. Colloids Surf. B Biointerfaces 2017, 152, 12-17. [CrossRef]

84. Dobrynin, A.V.; Deshkovskj, A.; Rubinstein, M. Adsorption of polyelectrolytes at oppositely charged surfaces. Macromolecules 2001, 34, 3421-3436. [CrossRef]

85. Dobrynin, A.V.; Deshkovskj, A.; Rubinstein, M. Adsorption of polyelectrolytes at an oppositely charged surface. Phys. Rev. Lett. 2000, 84, 3101. [CrossRef] [PubMed]

86. Bisht, H.S.; Chatterjee, A.K. Living free-radical polymerization-A review. J. Macromol. Sci. C 2007, 41, 139-173. [CrossRef]

87. Han, C.; Luque, R.; Dionysiou, D.D. Facile preparation of controllable size monodisperse anatase titania nanoparticles. Chem. Commun. 2012, 48, 1860-1862. [CrossRef]

88. de Gennes, P.G. Polymer Solutions near an Interface. 1. Adsorption and depletion layers. Macromolecules 1981, 14, 1637-1644. [CrossRef]

89. de Gennes, P.G. Polymers at an interface; a simplified view. Adv. Colloid Interface Sci. 1987, 27, 189-209. [CrossRef]

90. Feigin, R.I.; Napper, D.H. Depletion stabilization and depletion flocculation. J. Colloid Interface Sci. 1980, 75, 525-541. [CrossRef]

91. Tardani, F.; La Mesa, C. Attempts to control depletion in the surfactant-assisted stabilization of single-walled carbon nanotubes. Colloids Surf. A Physicochem. Eng. Asp. 2014, 443, 123-128. [CrossRef]

92. Giacalone, F.; Campisciano, V.; Calabrese, C.; la Parola, V.; Syrgiannis, Z.; Prato, M.; Gruttadauria, M. Single-walled carbon nanotube-polyamidoamine dendrimer hybrids for heterogeneous catalysis. ACS Nano 2016, 10, 4627-4636. [CrossRef] [PubMed]

93. Song, H. Metal hybrid nanoparticles for catalytic organic and photochemical transformations. Acc. Chem. Res. 2015, 48, 491-499. [CrossRef]

94. Meilikhov, M.; Yusenko, K.; Esken, D.; Turner, S.; van Tender, G.; Fischer, R.A. Metals@ MOFs-loading MOFs with metal nanoparticles for hybrid functions. Eur. J. Inorg. Chem. 2010, 3701-3714. [CrossRef]

95. Poupart, R.; Carbonnier, D.G.B.; le Droumaguet, B. Porous polymers and metallic nanoparticles: A hybrid wedding as a robust method toward efficient supported catalytic systems. Progr. Polym. Sci. 2019, 96, 21-42. [CrossRef]

96. Li, Y.; Fan, X.; Qi, J.; Ji, J.; Wang, S.; Zhang, G.; Zhang, F. Gold nanoparticles-graphene hybrids as active catalysts for Suzuki reaction. Mater. Res. Bull. 2010, 45, 1413-1418. [CrossRef]

97. Hakke, V.S.; Seepana, M.M.; Sanowane, S.H.; Kola, A.K.; Vooradi, R. Hybrid treatment technologies for the treatment of industrial wastewater. In Water Pollution and Remediation: Heavy Metals. Environmental Chemistry for a Sustainable World; Inamuddin, A.M.I., Lichtfouse, E., Eds.; Springer: Heidelberg, Germany, 2020; Volume 53, pp. 211-241.

98. Patil, B.B.T. Wastewater treatment using nanoparticles. J. Adv. Chem. Eng. 2015, 5, 1000131. 
99. Hu, B.; Yu, S.; Shi, C.; Gu, J.; Shao, Y.; Chen, Q.; Li, Y.; Mezzenga, R. Amyloid-Polyphenol hybrid nanofilaments mitigate colitis and regulate gut microbial dysbiosis. ACS Nano 2020, 14, 2760-2776. [CrossRef]

100. Thanki, K.; Zeng, X.; Justesen, S.; Tejlmann, S.; Falkenberg, E.; van Driessche, E.; Nielsen, H.; Franzyk, H.; Foged, C. Engineering of small interfering RNA-loaded lipidoid-poly(DL-lactic-co-glycolic acid) hybrid nanoparticles for highly efficient and safe gene silencing: A quality by design-based approach. Eur. J. Pharm. Biopharm. 2017, 120, 22-33. [CrossRef]

101. Heo, D.N.; Castro, N.J.; Lee, S.-J.; Noh, H.; Zhu, W.; Zhang, L.G. Enhanced bone tissue regeneration using a 3D printed microstructure incorporated with a hybrid nano hydrogel. Nanoscale 2017, 9, 5055-5062. [CrossRef]

102. Webster, A.; Greenman, J.; Haswell, S.J. Development of microfluidic devices for biomedical and clinical application. J. Chem. Technol. Biotechnol. 2011, 86, 10-17. [CrossRef]

103. Pang, L.; Shen, Y.; Hu, H.; Zeng, X.; Huang, W.; Gao, H.; Wang, H.; Wang, D. Chemically and physically cross-linked polyvinyl alcohol-borosilicate gel hybrid scaffolds for bone regeneration. Mat. Sci. Engin. C 2019, 105, 110076. [CrossRef]

104. Shalumon, K.T.; Kuo, C.-Y.; Wong, C.-B.; Chien, Y.-M.; Chen, H.-A.; Chen, J.-P. Gelatin/Nanohyroxyapatite Cryogel Embedded Poly(lactic-co-glycolic Acid)/Nanohydroxyapatite microsphere hybrid scaffolds for simultaneous bone regeneration and loadbearing. Polymers 2018, 10, 620. [CrossRef] [PubMed]

105. Mertaniemi, H.; Escobedo-Lucea, C.; Sanz-Garcia, A.; Gandía, C.; Mäkitie, A.; Partanen, J.; Ikkala, O.; Yliperttula, M. Human stem cell decorated nanocellulose threads for biomedical applications. Biomaterials 2016, 82, 208-220. [CrossRef]

106. Ansari, M.A.; Chung, I.-M.; Rajakumar, G.; Alzohairy, M.A.; Alomary, M.N.; Thiruvengadam, M.; Pottoo, F.H.; Ahmad, N. Current nanoparticle approaches in nose to brain drug delivery and anticancer therapy-A review. Curr. Pharm. Des. 2020, 26, 1128-1137. [CrossRef] [PubMed]

107. Dickinson, E. (Ed.) Food Polymers, Gels and Colloids; And Many Books in the Same Series; Woodhead Publishing Co.: Cambridge, UK, 1991.

108. La Mesa, C.; Risuleo, G. Some Remarks on Colloid Stability: Selected Examples Taken from the Milk Chain for Food Prepares. Colloids Interfaces 2020, 4, 58. [CrossRef]

109. Wijaya, W.; Patel, A.R.; Setiowati, A.D.; van der Meeren, P. Functional colloids from proteins and polysaccharides for food applications. Trends Food Sci. Technol. 2017, 68, 56-69. [CrossRef]

110. Yang, Y.; Shen, K.; Liu, Y.; Tan, Y.; Zhao, X.; Wu, J.; Niu, X.; Ran, F. Novel hybrid nanoparticles of vanadium nitride/porous carbon as an anode material for symmetrical supercapacitor. Nano Micro Lett. 2017, 9, 6. [CrossRef] [PubMed]

111. Lee, S.G.; Ham, D.S.; Lee, D.Y.; Bong, H.; Cho, K. Transparent superhydrophobic/translucent superamphiphobic coatings based on silica-fluoropolymer hybrid nanoparticles. Langmuir 2013, 29, 15051-15057. [CrossRef]

112. Sidik, N.A.C.; Adamu, I.M.; Jamil, M.M.; Kefayati, G.H.R.; Mamat, R.; Najafi, G. Recent progress on hybrid nanofluids in heat transfer applications: A comprehensive review. Intern. Comm. Heat Mass Trans. 2016, 78, 68-79. [CrossRef]

113. de Kruif, C.G.; Huppertz, T.; Urban, V.S.; Petukhov, A.V. Casein micelles and their internal structure. Adv. Colloid Interface Sci. 2012, 171-172, 36-52. [CrossRef] [PubMed] 